\title{
Identificação de QTL associados à simbiose entre Bradyrhizobium japonicum, B. elkanii e soja
}

\author{
Maria Aparecida dos Santos ${ }^{(1)}$, Marisa Fabiana Nicolás ${ }^{(2)}$ e Mariangela Hungria ${ }^{(1)}$
}

(1)Embrapa Soja, Caixa Postal 231, CEP 86001-970 Londrina, PR. E-mail: mapsan@cnpso.embrapa.br, hungria@cnpso.embrapa.br (2)Laboratório Nacional de Computação Científica, Av. Getúlio Vargas, no 333, Quitandinha, CEP 25651-075 Petrópolis, RJ. E-mail: marisa@Incc.br

\begin{abstract}
Resumo - O objetivo deste trabalho foi identificar QTL (locos de caráter quantitativo), utilizando marcadores do tipo microssatélites (SSR), relacionados à fixação biológica de nitrogênio (FBN), em uma população $\mathrm{F}_{2: 7}$ de cultivares de soja (Glycine max) com diferentes capacidades de FBN, Bossier (alta) e Embrapa 20 (média). Foram mapeados 16 marcadores, distribuídos em seis grupos de ligação, cobrindo uma região de $5 \%$ do genoma (151,6 cM). A análise de regressão identificou 12 associações significativas em quatro grupos de ligação (B1, C2, D1b e H): três para a massa da parte aérea seca, quatro para número de nódulos, duas para a massa de nódulos e três para a massa média de nódulos. Todos os QTL detectados foram de efeitos menores. Contudo, sete marcadores foram confirmados nas duas populações, indicativo de uso potencial em programas de melhoramento visando à FBN.
\end{abstract}

Termos para indexação: fixação biológica do nitrogênio, marcadores moleculares, mapa genético, microssatélites, nodulação, SSR.

\section{Identification of QTL associated with the symbiosis of Bradyrhizobium japonicum, B. elkanii and soybean}

\begin{abstract}
The objective of this work was to identify QTL (Quantitative Trait Loci) related to biological nitrogen fixation (BNF) using microsatellites (SSR) markers, in an $\mathrm{F}_{2: 7}$ population of soybean (Glycine max) cultivars with contrasting capacities of BNF, Bossier (high) and Embrapa 20 (medium). 16 markers located in six linkage groups have been mapped, covering about $5 \%$ of the genome $(151.6 \mathrm{cM})$. The regression analysis identified 12 significant associations in four linkage groups (B1, C2, D1b and H): three for shoot dry weight, four for nodule number, four for nodule weight and three for the medium value of nodule weight. All QTL had minor effects. However, seven QTL were confirmed in both populations, indicating that they might be effective in increasing BNF in soybean breeding programs.
\end{abstract}

Index terms: biological nitrogen fixation, molecular markers, genetic map, microsatellites, nodulation, SSR.

\section{Introdução}

O Brasil é o segundo maior produtor mundial de soja [Glycine max (L.) Merr.]. O levantamento da Companhia Nacional de Agricultura e Abastecimento, na safra 2004/2005, indicou incremento na área plantada de 4,9\%, comparativamente à safra anterior. $\mathrm{O}$ incremento na produção foi de $23,4 \%$, atingindo volume de 61,4 milhões de toneladas, enquanto o aumento na produtividade foi estimado em $17,6 \%$, resultando em uma média nacional de $2.751 \mathrm{~kg} \mathrm{ha}^{-1}$ (Conab, 2005).

Entre os principais fatores bióticos que contribuem para essa elevada produção de soja destaca-se a fixação biológica do nitrogênio (FBN), uma vez que a demanda de nitrogênio $(\mathrm{N})$ das cultivares brasileiras pode ser suprida totalmente pelo processo biológico, por meio da inoculação com estirpes selecionadas de Bradyrhizobium japonicum/B. elkanii.

Estudos indicam que a FBN pode suprir a soja em até $300 \mathrm{~kg} \mathrm{ha}^{-1}$ de $\mathrm{N}$; conseqüentemente, não se recomenda a utilização de fertilizantes nitrogenados, resultando em uma economia estimada em US\$ 3 bilhões por safra (Hungria \& Campo, 2005). O sucesso da fixação biológica de nitrogênio, no Brasil, é resultado de pesquisas e de seleção de estirpes compatíveis com as cultivares brasileiras, com alta eficiência de FBN e adaptadas às diferentes condições ambientais em que a soja é cultivada no país. Contudo, particularmente na última década, os caracteres da FBN não têm sido contemplados diretamente nos programas de melhoramento genético da soja, que priorizam características relacionadas com a produção e a resistência a doenças. Diferenças quanto à eficiência 
no processo de FBN, entre genótipos comerciais de soja utilizados atualmente, foram relatadas por Bohrer \& Hungria (1998) e Hungria \& Bohrer (2000), com indicações de perdas de até $30 \%$ na contribuição de $\mathrm{N}$ para as plantas, em comparação com as cultivares parentais.

Muito se conhece sobre genes nos rizóbios envolvidos na nodulação (nod, nol e noe) e no processo de FBN (nif e fix) (Stougaard, 2000); entretanto, pouco se sabe sobre os genes das leguminosas hospedeiras relacionados à simbiose. Estudos sobre nodulação em soja descrevem mutantes simbióticos tolerantes ao nitrato (nts) (Gremaud \& Harper, 1989; Akao \& Kouchi, 1992), ou com restrição à nodulação por determinados sorogrupos de Bradyrhizobium, incluindo genótipos não-nodulantes (Caldwell, 1966; Vest \& Caldwell, 1972; Devine, 1976). Um mapa integrado de ligação do genoma da soja (Cregan et al., 1999; Song et al., 2004) contendo alguns locos relacionados com restrição à nodulação (Rj1 e Rj2) e tolerância a nitrato (nts) foi recentemente obtido.

Alguns marcadores moleculares disponíveis no mapa do genoma da soja (Cregan et al., 1999; Song et al., 2004) vêm sendo utilizados para a identificação de QTL (locos de caráter quantitativo), visando seu emprego na seleção assistida em programas de melhoramento de soja. Por meio de marcadores do tipo microssatélites (seqüências simples repetidas, SSR), Meksem et al. (2001) identificaram regiões genômicas relacionadas com a produção de isoflavonóides. Marcadores RFLP (polimorfismo no comprimento de fragmentos de restrição) e SSR também foram utilizados para mapear QTL envolvidos com o incremento no teor de proteínas nos grãos (Sebolt et al., 2000). Schuster et al. (2001) mapearam quatro marcadores SSR ligados ao QTL de resistência ao nematóide do cisto (Heterodera glycine). QTL relacionados com resistência a nematóides de galha também foram mapeados por meio de marcadores SSR, em uma população de 96 linhagens $F_{2: 3}$, do cruzamento entre a PI96354 resistente e a cultivar Bossier, suscetível ao nematóide de galha (Meloidogyne incognita) (Li et al., 2001). Além disso, diversos QTL para características relacionadas com o rendimento de grãos já foram descritos (Orf et al., 1999a, 1999b; Chung et al., 2003).

Com relação à FBN, Nodari et al. (1993) detectaram quatro QTL que afetaram o número de nódulos em feijoeiro (Phaseolus vulgaris L.). Na soja, Nicolás et al. (2006) identificaram, em uma população de 160 famílias $\mathrm{F}_{2: 3}$ do cruzamento BRS 133 (baixa capacidade de FBN) x Embrapa 20 (média capacidade de FBN), 16 associações significativas entre marcadores SSR e QTL para parâmetros de crescimento e nodulação das plantas.

O objetivo deste trabalho foi avaliar QTL descritos previamente por Nicolás et al. (2006) e identificar novos QTL, pelo desenvolvimento de uma população de mapeamento de 157 linhagens $F_{2: 7}$ entre cultivares de soja, com diferentes capacidades de FBN, Bossier (alta) e Embrapa 20 (média).

\section{Material e Métodos}

\section{Material vegetal}

As análises foram conduzidas em população de mapeamento composta por 157 linhagens endogâmicas recombinantes, derivadas do cruzamento de duas cultivares previamente identificadas como tendo distintas capacidades de FBN, Bossier (alta) e Embrapa 20 (média), e com potencial genético de gerar linhas superiores (Nicolás et al., 2002). Uma amostra de 157 sementes $F_{2}$ foi avançada até a geração $F_{7}$ por meio do método do descendente de uma única semente (SSD). As linhagens $\mathrm{F}_{2: 7}$ foram avaliadas, em casa de vegetação, quanto às características relacionadas com o crescimento da planta (massa da parte aérea seca, MPAS) e nodulação (massa de nódulos secos, MNS; número de nódulos, NN; e massa média de nódulos secos, MNS/NN). O N total, acumulado nos tecidos, não foi analisado porque, em estudos prévios com 152 cultivares de soja, Bohrer \& Hungria (1998) e Hungria \& Bohrer (2000) constataram alta correlação entre os parâmetros de MPAS e $\mathrm{N}$ total acumulado pelas plantas $\left(r=0,87^{* *}\right.$ e $\left.r=0,92^{* *}\right)$, dispensando a necessidade de análise do teor de $\mathrm{N}$ nos tecidos.

\section{Análise das características de fixação biológica de nitrogênio e herdabilidade}

O experimento para avaliação das características de FBN (MNS, NN, MNS/NN, MPAS) foi conduzido em casa de vegetação, em vasos de plástico contendo $4 \mathrm{~kg}$ de solo não esterilizado e areia. O delineamento experimental foi inteiramente casualizado com oito repetições, com uma planta por repetição de cada uma das 157 linhagens $\mathrm{F}_{2: 7}$ (totalizando 1.256 plantas) e 15 repetições de cada genótipo parental. A fim de garantir boa nodulação, as plantas receberam $1 \mathrm{~mL}$ de inóculo misto (1:1, v/v) de Bradyrhizobium japonicum SEMIA 5079 e B. elkanii SEMIA 587. As estirpes desenvolveram-se em meio YM - yeast and mannitol (extrato de levedura e manitol) (Vincent, 1970) - por sete dias; cada uma das duas culturas foi ajustada para a concentração de $10^{9}$ células $\mathrm{mL}^{-1} \mathrm{e}$, depois, misturadas. A inoculação foi 
realizada quando as plantas atingiram o estádio V2 (primeira folha trifoliada estendida e a segunda folha suficientemente aberta) (Fehr \& Caviness, 1977). Depois de 30 dias da inoculação, as plantas foram coletadas individualmente. O sistema radicular e a parte aérea foram separados e mantidos em estufa com circulação forçada de ar, a $65^{\circ} \mathrm{C}$, por quatro dias. A seguir, avaliaram-se os parâmetros MPAS, NN, MNS e a relação MNS/NN.

Os dados coletados foram submetidos à análise de variância, usando o procedimento GLM, do SAS Institute (1989). A herdabilidade de cada característica foi obtida por meio da fórmula: $h^{2}=\sigma^{2} \mathrm{~g} /\left[\sigma^{2} \mathrm{~g}+\left(\sigma^{2} \mathrm{e} / \mathrm{r}\right)\right]$, em que $\sigma^{2} \mathrm{~g}$ é a variância genotípica; $\sigma^{2}$ é a variância do erro; e r é o número de repetições (Wricke \& Weber, 1986).

\section{Marcadores moleculares}

As amostras de DNA foram extraídas a partir de duas a três folhas (primeiras folhas trifoliadas) de cada uma das 157 linhagens $\mathrm{F}_{2: 7}$ e das cultivares parentais Bossier e Embrapa 20, pelo método descrito por Keim et al. (1988). A seguir, cada amostra de DNA genômico total foi amplificada com 24 pares de iniciadores microssatélites, escolhidos a partir do mapa do genoma da soja (Cregan et al., 1999) (Tabela 1). O volume total das reações de PCR foi modificado para $10 \mu \mathrm{L}$, contendo tampão de PCR 1X (2,5 mM Tris-HCL pH 8,3 e $62,5 \mathrm{mM}$ de $\mathrm{KCl}$ ), 2,5 mM de $\mathrm{MgCl}_{2}, 125 \mu \mathrm{M}$ de cada dNTP, 0,2 $\mu \mathrm{M}$ de cada oligonucleotídeo iniciador (forward e reverse), uma unidade de Taq DNA polimerase e 20 ng de DNA genômico. As amplificações foram realizadas em um termociclador (MJ Research modelo PT-200), com um programa iniciado com 7 minutos a $94^{\circ} \mathrm{C}$, seguido de 30 ciclos de 1 minuto a $94^{\circ} \mathrm{C}, 1$ minuto a $50^{\circ} \mathrm{C}$ e 2 minutos a $72^{\circ} \mathrm{C}$, e finalizado com uma etapa de 7 minutos a $72^{\circ} \mathrm{C}$, para a extensão da fita. Os fragmentos foram separados por eletroforese em gel de agarose a $3 \%$, em tampão TBE $0,5 \mathrm{X}$ (Tris-Borato 0,09 M e EDTA 0,002 M) por, aproximadamente, 4 horas de corrida a $90 \mathrm{~V}$, ou em gel de poliacrilamida a 10\% (29:1, acrilamida:bis-acrilamida), quando não foi possível visualizar o polimorfismo em gel de agarose. Os géis

Tabela 1. Seqüências dos oligonucleotídeos dos 24 marcadores utilizados na população de linhagens endogâmicas recombinantes derivadas do cruzamento entre as cultivares Bossier e Embrapa 20.

\begin{tabular}{|c|c|c|c|}
\hline Locus & $\mathrm{GL}^{(1)}$ & Oligonucleotídeo iniciador fita senso (5') & Oligonucleotídeo iniciador fita anti-senso (3') \\
\hline Satt187 & A2 & GCGTTTTAATTTATGATATAACCAA & GCGTTTTATCTCTTTTTCCACAAC \\
\hline Satt233 & $\mathrm{A} 2$ & AAGCATACTCGTCGTAAC & GCGGTGCAAAGATATTAGAAA \\
\hline Satt509 & B1 & GCGCTACCGTGTGGTGGTGTGCTACCT & GCGCAAGTGGCCAGCTCATCTATT \\
\hline Satt197 & B1 & CACTGCTTTTTCCCCTCTCT & AAGATACCCCCAACATTATTTGTAA \\
\hline Satt332 & B1 & GCGCATCCAGGGCTTGCAACAAAG & GCGGTCCTTATATATGGAAGATCA \\
\hline Satt444 & $\mathrm{B} 1$ & TGCAAAAATACGGGTTCATAAT & AGAGGAAGCGAGACTAATAGAAG \\
\hline Satt416 & B2 & TATAGCCCAGCAAAAAAAAACAGAGAT & ATCAAAACCGACCAATGAACAAAAAAA \\
\hline Sct_094 & $\mathrm{B} 2$ & GGGTGAAGTGAGAGTAACA & CCCGGATCTCTTCATT \\
\hline Satt560 & $\mathrm{B} 2$ & GCGATCGTGCAAGAAAATA & GCGGTGGACTTCGCCTCAAATAAT \\
\hline Satt307 & $\mathrm{C} 2$ & GCGCTGGCCTTTAGAAC & GCGTTGTAGGAAATTTGAGTAGTAAG \\
\hline Satt202 & $\mathrm{C} 2$ & GGAATGCATGAGTATTAACCTCTTAT & GGGCTAACGAACATGTAACTTATCAAC \\
\hline Satt371 & $\mathrm{C} 2$ & TGCAAACTAACTGGATTCACTCA & GAGATCCCGAAATTTTAGTGTAACA \\
\hline Satt558 & $\mathrm{D} 1 \mathrm{~b}$ & СТСАСАСССТТТСАТТАТСТА & AAATCGCGCATCTAAATTTAC \\
\hline Satt296 & $\mathrm{D} 1 \mathrm{~b}$ & GCCCCACAACCAGAAACAC & GAAATTTGGCGACTAAAAACTGC \\
\hline Satt325 & $\mathrm{F}$ & GCGGGGTATTAAGGGAAAACAAAA & GCGTAAACGAACAATCACTTCATA \\
\hline Satt288 & G & GCGGGGTGATTTAGTGTTTGACACCT & GCGCTTATAATTAAGAGCAAAAGAAG \\
\hline Satt192 & $\mathrm{H}$ & CACCGCTGATTAAGATTTTT & CGCTGAGTTGTTTTCATC \\
\hline Satt181 & $\mathrm{H}$ & TGGCTAGCAGATTGACA & GGAGCATAGCTGTTAGGA \\
\hline Satt434 & $\mathrm{H}$ & GCGTTCCGATATACTATATAATCCTAAT & GCGGGGTTAGTCTTTTTATTTAACTTAA \\
\hline Satt406 & $\mathrm{J}$ & GCGTGAGCATTTTTGTTT & TGACGGGTTTAATAGCAT \\
\hline Satt539 & $\mathrm{K}$ & GCGGTTGTAATTTAATGAACACATT & GCGGATTTTGGACTGGATTAAATAA \\
\hline Satt232 & $\mathrm{L}$ & GCGGCGTGAATAGTATACGTTGAGA & GCGGACATAAATGCAATCACTTAAAAAG \\
\hline Sat_084 & $\mathrm{N}$ & AAAAAAGTATCCATGAAACAA & TTGGGACCTTAGAAGCTA \\
\hline Satt584 & $\mathrm{N}$ & GCGCCCAAACCTATTAAGGTATGAACA & GCGGGTCAGAAGATGCTACCAAACTCT \\
\hline
\end{tabular}

${ }^{(1)}$ Grupo de ligação, como descrito em Cregan et al. (1999). 
foram corados em solução de brometo de etídio $\left(0,5 \mu \mathrm{g} \mathrm{mL}^{-1}\right)$ por 30 minutos e fotografados sob luz ultravioleta com câmera digital Kodak DC 120 e software para PC Kodak Digital Science 1D (Eastman Kodak Company). A partir do perfil das bandas nos géis, foi construída uma matriz de dados numéricos para cada marcador, considerando-se como 1, a presença da banda da parental Bossier e 2, a presença da banda da parental Embrapa 20. Testes de $\chi^{2}$ foram usados para confirmar a herança monogênica dos marcadores moleculares.

\section{Identificação e mapeamento de QTL}

O mapa genético foi construído com base nos marcadores moleculares que segregaram, de acordo com a proporção esperada de herança monogênica em cada linhagem, ou seja, 1:1. Os cálculos da freqüência de recombinação, da distância genética entre os diferentes marcadores genéticos e da determinação do posicionamento dos marcadores foram feitos com auxílio do programa Mapmaker/Exp (Lander et al., 1987). $\mathrm{O}$ agrupamento dos marcadores foi feito utilizando os mesmos critérios adotados por Nicolás et al. (2006), com valor limite de deteç̧ão (LOD) de 3,0, e a conversão da freqüência de recombinação para centimorgans (cM) foi feita utilizando a distância de mapeamento de Haldane
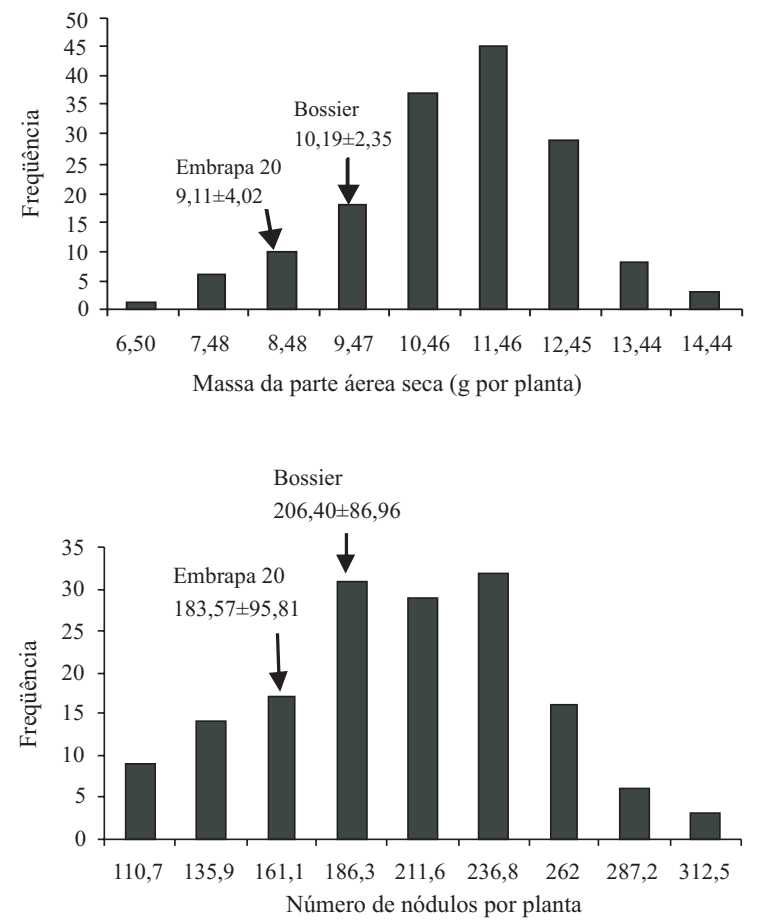

$(r=0,50)$. A identificação de marcadores moleculares, associados às características MPAS, MNS, NN e MNS/ $\mathrm{NN}$, foi feita pela análise de regressão simples. As linhagens heterozigotas para os marcadores foram incluídas nas análises, mas suas médias não foram apresentadas. A existência de ligação entre um loco marcador e um caráter quantitativo foi admitida quando houve diferença significativa $(p \leq 0,05)$ entre o valor fenotípico médio da linhagem $\mathrm{F}_{2: 7}$ e o marcador. A proporção da variação fenotípica, explicada pela associação caráter-marcador, foi estimada pelo coeficiente de determinação ( $\left.\mathrm{R}^{2}\right)$ (Edwards et al., 1987). Todas as análises foram feitas com o procedimento PROC GLM (SAS Institute, 1989).

\section{Resultados e Discussão}

\section{Análise das características de nodulação e crescimento da planta}

A distribuição de freqüência das características relacionadas com o crescimento da planta (MPAS) e a nodulação (MNS, NN e MNS/NN), para as 157 linhagens, não apresentou desvios significativamente diferentes da normalidade, confirmando que as características fenotípicas são quantitativas (Figura 1). A cultivar

Figura 1. Distribuição de freqüências para massa da parte aérea seca e nodulação em linhagens endogâmicas recombinantes $\mathrm{F}_{2: 7}$, do cruzamento das cultivares de soja, Bossier e Embrapa 20, com inoculação de Bradyrhizobium. As setas indicam as médias das parentais com o desvio-padrão. 
parental Bossier apresentou as maiores médias em todas as características avaliadas - MPAS $(10,19 \pm 2,35$ g por planta), MNS $(699,93 \pm 331,77 \mathrm{mg}$

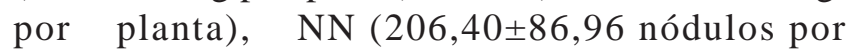
planta), MNS/NN $(4,04 \pm 2,28)$ - em relação à Embrapa 20 - MPAS $(9,11 \pm 4,02$ g por planta), MNS (529,96 $\pm 347,30 \mathrm{mg}$ por planta), NN $(183,57 \pm 95,81$ nódulos por planta) e MNS/NN $(2,75 \pm 1,28)$. O comportamento das cultivares parentais foi semelhante ao verificado por Nicolás et al. (2002).

$\mathrm{Na}$ análise de variância, foram observadas diferenças significativas entre as linhagens em todas as características avaliadas (Tabela 2), indicando a existência de variabilidade genética. Os coeficientes de variação $(\mathrm{CV})$ para MPAS, MNS, NN e MNS/NN foram de 25,60, $49,85,50,12$ e $45,60 \%$, respectivamente, mas valores superiores a $30 \%$ são comumente relatados para os parâmetros de nodulação (Bohrer \& Hungria, 1998; Hungria \& Bohrer, 2000; Nicolás et al., 2002). A importância de avaliação dos parâmetros de MNS foi salientada nos estudos de Bohrer \& Hungria (1998) e Hungria \& Bohrer (2000), de avaliação de 152 cultivares de soja, onde foi demonstrado que a MNS estava altamente correlacionada tanto com a MPAS (valores entre $\mathrm{r}=0,68^{* *}$ e $\mathrm{r}=0,80^{* *}$ ), quanto com o $\mathrm{N}$ total acumulado na planta (valores entre $r=0,65^{* *}$ e $r=0,74 * *$ ). As linhagens apresentaram segregação transgressiva semelhante à previamente descrita por Nicolás et al. (2002) para o cruzamento BRS 133 x Embrapa 20.

Os valores de herdabilidade estimados foram de $49 \%$ para MPAS, 30\% para NN, 33\% para MNS e 27\% para MNS/NN, os quais estão de acordo com os coeficientes de determinação $\left(\mathrm{R}^{2}\right)$ (Tabela 2), denotando a natureza complexa dos caracteres relacionados ao crescimento e à nodulação, que estão sujeitos à interação com o ambiente.

\section{Polimorfismo dos marcadores microssatélites e construção do mapa de ligação}

Ao todo, 136 marcadores SSR foram testados quanto ao polimorfismo, sendo 66 polimórficos entre as

Tabela 2. Variância para massa da parte aérea seca (MPAS), número de nódulos (NN), massa de nódulos secos (MNS) e relação MNS/NN nas linhagens $\mathrm{F}_{2: 7}$ do cruzamento Bossier $\mathrm{x}$ Embrapa 20.

\begin{tabular}{lrrrccc}
\hline Variável & Quadrado médio & GL & $\mathrm{F}$ & $\mathrm{p}$ & $\mathrm{R}^{2}$ & $\mathrm{CV}(\%)$ \\
\hline MPAS & 17,1176 & 156 & 1,98 & 0,0001 & 0,2280 & 25,60 \\
NN & $16.831,6510$ & 156 & 1,44 & 0,0008 & 0,1768 & 50,12 \\
MNS & $210.989,8000$ & 156 & 1,49 & 0,0002 & 0,1822 & 49,85 \\
MNS/NN & 4,1040 & 156 & 1,37 & 0,0034 & 0,1695 & 45,60 \\
\hline
\end{tabular}

parentais Bossier e Embrapa 20. Foram avaliados 24 desses marcadores polimórficos nas 157 linhagens (Tabela 1). Todos os marcadores segregaram de acordo com a proporção esperada (1:1), segundo o teste do $\chi^{2}$. Foi possível mapear 16 marcadores em seis grupos de ligação (LG, linkage group), correspondendo aos grupos B1, C2, D1b, H, N e B2, do mapa de Cregan et al. (1999). Foram constatadas algumas diferenças em relação às distâncias entre os marcadores SSR obtidas neste trabalho e as populações descritas por Cregan et al. (1999) e Nicolás et al. (2006) (Figura 2), possivelmente em virtude do erro experimental e das diferenças entre as parentais. Resultados semelhantes foram relatados por Ghassemi \& Gresshoff (1998) e Chung et al. (2003). Os locos mapeados cobrem uma região de 5\% do genoma da soja (151,6 cM). Desse modo, outros marcadores estão sendo utilizados para conseguir maior cobertura do genoma e saturar as regiões mapeadas.

\section{Marcadores associados com o crescimento da planta e a nodulação}

As análises de regressão, com os locos marcadores como variáveis independentes e os fenótipos (MPAS, NN, MNS, MNS/NN) como variáveis dependentes, identificaram 12 associações significativas entre locos marcadores e QTL relacionadas a efeitos aditivos (Tabela 3). Os marcadores que apresentaram associações significativas com QTL para crescimento e nodulação foram mapeados em quatro grupos de ligação - B1 (Satt509, Satt197, Satt332), C2 (Satt307, Satt202), D1b (Satt296) e H (Satt192, Satt434) (Figura 2). Dois marcadores, Satt232 e Satt325, que também apresentaram associações significativas nas características fenotípicas, não foram agrupados.

Quanto à característica MPAS, três marcadores foram significativamente associados: Satt332, Satt434 e Satt232. No NN, quatro associações foram significativas: Satt197, Satt509, Satt307 e Satt325. Na MNS, duas associações foram significativas: Satt202 e Satt307. Quanto à relação MNS/NN, três associações foram significativas: Satt296, Satt192 e Satt509. O porcentual de variação fenotípica $\left(\mathrm{R}^{2}\right)$, explicado pelas associações loco marcador e QTL, variou de 3,7 a 5,0\% para MPAS, de 2,50 a 5,25\% para NN, de 3,3 a 8,0\% para MNS e de 2,5 a 3,8\% para MNS/ NN (Tabela 3).

Todos os QTL detectados foram de efeitos menores, de modo semelhante ao encontrado na população $F_{2: 3}$ 
de BRS 133 x Embrapa 20 (Nicolás et al., 2006). A baixa magnitude dos efeitos dos QTL detectados coincide com os baixos valores de herdabilidade das características avaliadas. Resultados semelhantes têm sido relatados em vários estudos de QTL para características com herdabilidade moderada ou baixa. Loudet et al. (2003) identificaram 57 QTL com efeitos pequenos relacionados à eficiência no uso de $\mathrm{N}$ em linhagens recombinantes de Arabidopsis thaliana ( $\mathrm{R}^{2}$ entre 2 e 21). Em soja, QTL de efeitos menores também foram relatados em

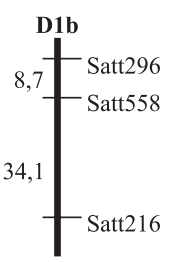

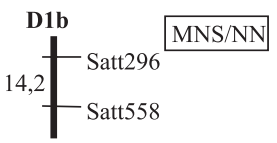
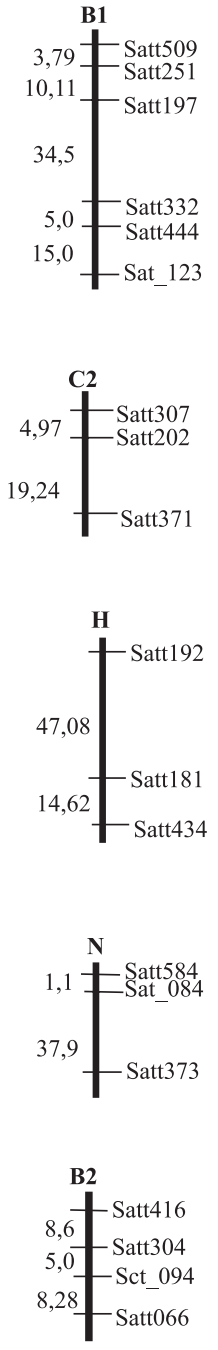

$$
\text { USDA/Iowa St. Univ. }{ }^{(1)}
$$
Cregan et al. (1999)
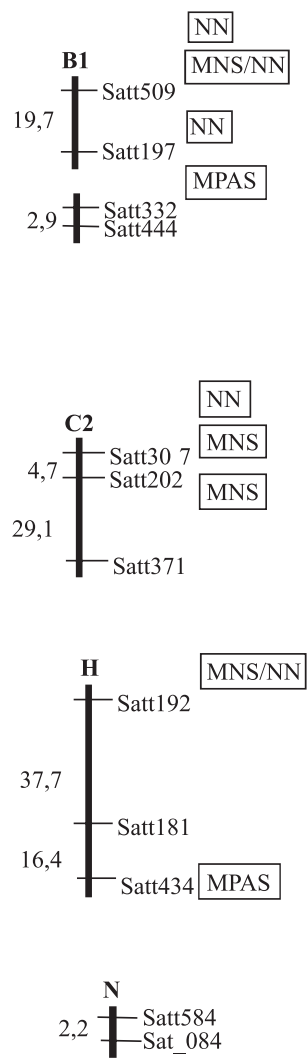

N

Satt373 MPAS

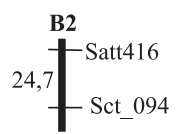

Bossier e Embrapa $20^{(2)}$
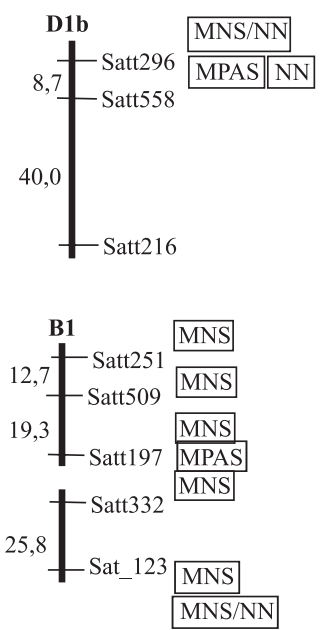

C2

Satt307 NN

Figura 2. Mapa parcial de ligação genética, baseado na informação de 24 locos SSR da população de 157 linhagens recombinantes $\left(\mathrm{F}_{2: 7}\right)$ do cruzamento Bossier x Embrapa 20. O mapa foi construído utilizando a função de mapeamento de ${ }^{(1)}$ Kosambi e ${ }^{(2)}$ Haldane. 
características relacionadas com o rendimento de grãos (Orf et al., 1999a, 1999b; Yuan et al., 2002) e com a concentração de proteínas e óleo na semente (Sebolt et al., 2000). Pela análise de regressão, não é possível distinguir um QTL de efeito pequeno, situado muito próximo ao marcador de um QTL de grande efeito, mais distante. Principalmente em mapas de baixa densidade de marcadores, a posição do QTL não pode ser precisamente determinada, em virtude da não independência entre os testes de hipótese para ligação, que confundem o efeito do QTL e sua posição (Liu, 1998); estes fatores também podem explicar o baixo efeito dos QTL detectados.

Por outro lado, os marcadores Satt509 e Satt307 foram associados com mais de uma característica fenotípica (Figura 2). Marcadores associados a mais de uma característica também foram identificados na população $\mathrm{F}_{2: 3}$ de $\mathrm{BRS} 133$ x Embrapa 20 (Figura 2). Isso indica que essas características fenotípicas são controladas por QTL estreitamente ligados ou pela ação de um único QTL com efeito pleiotrópico (Lebreton et al., 1995; Loudet et al., 2003). QTL com efeitos pleiotrópicos já foram observados em vários caracteres morfológicos e de desenvolvimento na soja e no feijoeiro (Keim et al., 1990; Mansur et al., 1993; Nodari et al., 1993; Souza et al., 2000; Nicolás et al., 2006). A maior dificuldade que se apresenta diante desse tipo de interações consiste em distinguir QTL fortemente ligados, que afetam várias características, de um único QTL com efeitos pleiotrópicos.

Tabela 3. Distribuição da ligação de marcadores SSR mostrando associações significativas com as diferenças fenotípicas para massa da parte aérea seca (MPAS), número de nódulos (NN), massa de nódulos secos (MNS) e relação MNS/NN, como resultado da análise de regressão.

\begin{tabular}{|c|c|c|c|c|c|c|}
\hline $\begin{array}{l}\text { Característica } \\
\text { quantitativa }\end{array}$ & Marcador & $\begin{array}{l}\text { Grupo de } \\
\text { ligação }^{(1)}\end{array}$ & $\begin{array}{l}\text { Teste } \\
\mathrm{F}^{(2)}\end{array}$ & $\mathrm{R}^{2}(\%)$ & $\mathrm{A}_{1} \mathrm{~A}_{1}^{(3)}$ & $\mathrm{A}_{2} \mathrm{~A}_{2}{ }^{(3)}$ \\
\hline MPAS & Satt332 & B1 & 0,01 & 3,7 & $11,19 b$ & $11,76 \mathrm{a}$ \\
\hline \multirow[t]{2}{*}{ (mg por planta) } & Satt434 & $\mathrm{H}$ & 0,03 & 3,1 & $11,18 b$ & $11,72 \mathrm{a}$ \\
\hline & Satt232 & $\mathrm{L}$ & 0,005 & 5,0 & $11,84 \mathrm{a}$ & $11,20 \mathrm{~b}$ \\
\hline NN & Satt197 & B1 & 0,05 & 2,5 & $207,47 a$ & $222,27 b$ \\
\hline \multirow{3}{*}{$\begin{array}{l}\text { (nódulo por } \\
\text { planta) }\end{array}$} & Satt509 & B1 & 0,004 & 5,25 & $203,19 b$ & $224,93 a$ \\
\hline & Satt307 & $\mathrm{C} 2$ & 0,0025 & 6,2 & $228,58 \mathrm{a}$ & $205,28 b$ \\
\hline & Satt325 & $\mathrm{F}$ & 0,016 & 3,8 & $229,88 \mathrm{a}$ & $209,67 b$ \\
\hline \multirow{5}{*}{$\begin{array}{l}\text { MNS } \\
\text { (mg por planta } \\
\text { MNS/NN } \\
\text { (mg por nódulo) }\end{array}$} & Satt202 & $\mathrm{C} 2$ & 0,022 & 3,3 & $783,00 \mathrm{a}$ & $718,30 \mathrm{~b}$ \\
\hline & Satt307 & $\mathrm{C} 2$ & 0,0005 & 8,0 & $802,51 \mathrm{a}$ & $706,90 \mathrm{~b}$ \\
\hline & Satt296 & D1b & 0,03 & 3,0 & $3,71 \mathrm{~b}$ & $3,98 a$ \\
\hline & Satt192 & $\mathrm{H}$ & 0,03 & 3,8 & $3,93 a$ & $3,68 b$ \\
\hline & Satt509 & $\mathrm{B} 1$ & 0,05 & 2,5 & $3,93 \mathrm{a}$ & $3,69 \mathrm{a}$ \\
\hline
\end{tabular}

(1)Grupo de ligação como descrito em Cregan et al. (1999). (2)Nível de significância. ${ }^{(3)}$ Medias alélicas do marcador associadas aos parentais Bossier $\left(A_{1} A_{1}\right)$ e Embrapa $20\left(A_{2} A_{2}\right)$. Valores seguidos pela mesma letra não diferem significativamente pelo teste de Tukey a $5 \%$ de probabilidade.

\section{Verificação de QTL mapeados nas famílias $F_{2: 3}$ do cruzamento BRS 133 x Embrapa 20}

Entre os marcadores utilizados na população $\mathrm{F}_{2: 7}$ de Bossier x Embrapa 20, oito haviam sido mapeados anteriormente na população $\mathrm{F}_{2: 3}$ de BRS $133 \mathrm{x}$ Embrapa 20 (Nicolás et al., 2006), associados significativamente às características de crescimento e nodulação (Figura 2). Os marcadores Satt296, Satt232 e Satt197, que foram associados com a MPAS na população BRS 133 x Embrapa 20, foram utilizados para verificar MPAS na população Bossier x Embrapa 20. A associação com o Satt232 foi confirmada, mas ainda não foi ancorada com outro marcador no grupo L, razão pela qual não está representada na Figura 1. Para seis marcadores (Sat296, Satt509, Satt197, Satt332, Sat307 e Satt192) associados com parâmetros de nodulação (MNS, NN ou MNS/NN), na população BRS 133 x Embrapa 20, foi confirmada a associação com QTL na população Bossier x Embrapa 20 (Figura 2). Além disso, o Satt232 foi associado à MPAS nas duas populações e, como as plantas cresceram em condições de maximização de FBN, onde existe alta correlação entre a massa nodular e a biomassa das plantas (Bohrer \& Hungria, 1998; Hungria \& Bohrer, 2000), esse marcador também deve estar associado à FBN.

Alguns QTL encontrados em BRS 133 x Embrapa 20 (Nicolás et al., 2006), porém, não foram confirmados em Bossier x Embrapa 20, e vice-versa. Uma hipótese da não confirmação de alguns QTL poderia ser a de que os alelos no QTL estejam fixados na população (ambos parentais possuem os mesmos alelos para esse QTL) e, nesse caso, os eventos de segregação não podem ser detectados (Mian et al., 1998). É possível, também, que marcadores detectados em $\mathrm{F}_{2: 3}$ BRS 133 x Embrapa 20 não fossem confirmados em uma população mais avançada, como a deste estudo. Avaliando a ocorrência de QTL nas características relacionadas com a produção em soja, em três diferentes populações de linhagens recombinantes, Orf et al. (1999b) verificaram que alguns QTL eram identificados nas três populações, outros em duas, bem como constataram a ocorrência de QTL identificados em apenas uma população. Nesse contexto, a base genética também pode contribuir para a identificação. Entretanto, a ausência de um QTL não pode ser simplesmente atribuída à falta de oportunidade de estabelecimento de ligação entre o loco marcador e QTL. Em muitos casos, a associação entre um marcador e o QTL pode ser falso-positiva, ou erro tipo 1 (Dudley, 1993), isto é, quando se aceita uma 
hipótese, mas ela não é significativa. Os estudos sobre confirmação de QTL detectados em soja são limitados e conflitantes, sendo necessária a avaliação da consistência desses estudos em diferentes populações e ambientes, para posterior uso desses QTL nos programas de melhoramento (Fasoula et al., 2004).

Os marcadores Satt251 e Satt373, que apresentaram associação significativa para MNS e MPAS, respectivamente, e Satt066 (Figura 2), associado aos parâmetros MNS e MNS/NN, na população BRS 133 x Embrapa 20, não foram avaliados na população deste estudo; contudo, já se constatou polimorfismo entre os genótipos parentais. Desse modo, novas análises estão sendo realizadas. Quanto ao marcador Sat_123, associado a MNS e MNS/NN (Figura 2), será verificada a existência de polimorfismo entre as cultivares parentais Bossier e Embrapa 20. Além disso, outros marcadores deverão ser testados quanto ao polimorfismo e analisados nesta população, para saturar as regiões já mapeadas e identificar novas associações.

Este estudo representa a etapa inicial na identificação e na confirmação de QTL associados com a simbiose em cultivares brasileiras de soja. Sete marcadores previamente identificados na população $F_{2: 3}$ do cruzamento BRS 133 x Embrapa 20 foram confirmados na população $F_{2: 7}$ de Bossier x Embrapa 20. Esses microssatélites consistem na primeira indicação para utilização de marcadores moleculares em programas de melhoramento que visam a incrementar a contribuição da FBN em soja.

\section{Conclusões}

1. Seis marcadores moleculares do tipo microssatélite (Sat296, Satt509, Satt197, Satt332, Sat307 e Satt192) foram identificados e relacionados à nodulação, e o marcador Satt232 mostrou estar relacionado à produção de biomassa em soja.

2. Esses marcadores podem ser utilizados em programas de melhoramento visando ao incremento na contribuição da fixação biológica do nitrogênio em soja.

\section{Agradecimentos}

À Taila C. S. Vedovati, à Ednéia Borges, ao Manoel P. da Silva, ao Rinaldo B. Conceição e à Ligia M. O. Chueire, pelo apoio na condução do experimento e nas análises laboratoriais; ao Fernando G. Barcelos, pelas sugestões no texto; ao Carlos A. Arias, pelo esclare- cimento das dúvidas nas análises do experimento; à Capes, pela concessão de bolsa; ao CNPq, pelo financiamento ao projeto.

\section{Referências}

AKAO, S.; KOUCHI, H. A supernodulating mutant isolated from soybean cultivar Enrei. Soil Science and Plant Nutrition, v.38, p.183-188, 1992.

BOHRER, T.R.J.; HUNGRIA, M. Avaliação de cultivares de soja quanto à fixação biológica do nitrogênio. Pesquisa Agropecuária Brasileira, v.33, p.937-953, 1998.

CALDWELL, B.E. Inheritance of a strain-specific ineffective nodulation in soybeans. Crop Science, v.6, p.427-428, 1966.

CHUNG, J.; BABKA, H.L.; GRAEF, G.L.; STASWICK, P.E.; LEE, D.J.; CREGAN, P.B.; SHOEMAKER, R.C.; SPECHT, J.E. The seed protein, oil, and yield QTL on soybean linkage group I. Crop Science, v.43, p.1053-1067, 2003.

CONAB. Soja - Brasil: série histórica de área plantada, safras 1990/91 a 2004/05 em mil hectares. Disponível em: <http:// www.conab.gov.br/download/safra/SojaSerieHist.xls>. Acesso em: 28 jan. 2005.

CREGAN, P.B.; JARVIK, T.; BUSH, A.L.; SHOEMAKER, R.C.; LARK, K.G.; KAHLER, A.L.; KAYA, N.; VAN TOAI, T.T.; LOHNES, D.G.; CHUNG, J.; SPECHT, J.E. An integrated genetic linkage map of the soybean genome. Crop Science, v.39, p.14641490, 1999.

DEVINE, T.E. Genetic studies of soybean host cultivar interactions with Rhizobium strains. Soybean Genetics Newsletter, v.3, p.1920, 1976.

DUDLEY, J.W. Molecular markers in plant improvement: manipulation of genes affecting quantitative traits. Crop Science, v.33, p.660-668, 1993.

EDWARDS, M.D.; STUBER, C.W.; WENDEL, J.F. Molecularmarker facilitated investigations of quantitative-trait loci in maize. I. Numbers, genomic distribution and types of gene action. Genetics, v.116, p.113-125, 1987.

FASOULA, V.A.; HARRIS, D.K.; BOERMA, H.R. Validation and designation of quantitative trait loci for seed protein, seed oil, and seed weight from two soybean populations. Crop Science, v.44, p.1218-1225, 2004.

FEHR, W.R.; CAVINESS, C.E. Stages of soybean development. Ames: Iowa State University, 1977. (Special report, 80).

GHASSEMI, F.; GRESSHOFF, P.M. The early enod2 and the leghemoglobin $(l b c 3)$ genes segregate independently from other known soybean symbiotic genes. Molecular Plant-Microbe Interactions, v.11, p.6-13, 1998.

GREMAUD, M.F.; HARPER, J.E. Selection and initial characterization of partially nitrate tolerant nodulation mutants of soybean. Plant Physiology, v.89, p.169-173, 1989.

HUNGRIA, M.; BOHER, T.R.J. Variability of nodulation and dinitrogen fixation capacity among soybean cultivars. Biology and Fertility of Soils, v.31, p.45-52, 2000. 
HUNGRIA, M.; CAMPO, R.J. Fixação biológica do nitrogênio em sistemas agrícolas. In: CONGRESSO BRASILEIRO DE CIÊNCIA DO SOLO, 30., 2005, Pernambuco. Solos, sustentabilidade e qualidade ambiental. Pernambuco: SBCS, UFPE; Rio de Janeiro: Embrapa Solos, 2005. p.1-30. CD-ROM.

KEIM, P.; OLSON, T.C.; SHOEMAKER, R.C. A rapid protocol for isolating soybean DNA. Soybean Genetics Newsletter, v.15, p.150-152, 1988.

KEIM, P.; DIERS, B.W.; OLSON, T.C.; SHOEMAKER, R.C. RFLP mapping in soybean: association between marker loci and variation in quantitative traits. Genetics, v.126, p.735-742, 1990.

LANDER, E.S.; GREEN, P.; ABRAHAMSON, J.; BARLOW, A.; DALY, M.J.; LINCOLN, S.E.; NEWBURG, L. Mapmaker: an interactive computer package for constructing primary genetic linkage maps or experimental and natural populations. Genomics, v.1, p.174181, 1987.

LEBRETON, C.; LAZIC-JANCIC, V.; STEED, A.; PEKIC, S.; QUARRIE, S.A. Identification of QTL for drought responses in maize and their use in testing causal relationships between traits. Journal of Experimental Botany, v.46, p.853-865, 1995.

LI, Z.; JAKKULA, L.; HUSSEY, R.S.; TAMULONIS, J.P.; BOERMA, H.R. SSR mapping and confirmation of the QTL from PI96354 conditioning soybean resistance to southern root-knot nematode. Theoretical and Applied Genetics, v.103, p.1167-1173, 2001.

LIU, B.-H. Statistical genomics: linkage, mapping, and QTL analysis. Boca Raton: CRC Press, 1998. 611p.

LOUDET, O.; CHAILLOU, S.; MERIGOUT, P.; TALBOTEC, J.; DANIEL-VEDELE, F. Quantitative trait loci analysis of nitrogen use efficiency in Arabidopisis. Plant Physiology, v.131, p.345-358, 2003.

MANSUR, L.M.; LARK, K.G.; KROSS, H.; OLIVEIRA, A. Interval mapping of quantitative trait loci for reproductive, morphological, and seed traits of soybean (Glycine max L.). Theoretical and Applied Genetics, v.86, p.907-913, 1993.

MEKSEM, K.; NJITI, V.N.; BANZ, W.J.; IQBAL, M.J.; KASSEM, MY.M.; HYTEN, D.L.; YUANG, J.; WINTERS, T.A.; LIGHTFOOT, D.A. Genomic regions that underlie soybean seed isoflavone content. Journal of Biomedicine and Biotechnology, v.1, p.38-44, 2001.

MIAN, M.A.R.; ASHLEY, D.A.; BOERMA, H.R. An additional QTL for water use efficiency in soybean. Crop Science, v.38, p.390393, 1998.

NICOLÁS, M.F.; ARIAS, C.A.A.; HUNGRIA, M. Genetics of nodulation and nitrogen fixation in Brazilian soybean cultivars. Biology and Fertility of Soils, v.36, p.109-117, 2002.

NiCOLÁS, M.F.; HUNGRIA, M.; ARIAS, C.A.A. Identification of quantitative trait loci controlling nodulation and shoot mass in progenies from two Brazilian soybean cultivars. Field Crops Research, v.95, p.355-366, 2006.
NODARI, R.O.; TSAI, S.M.; GUZMÁN, P.; GILBERTSON, R.L.; GEPTS, P. Toward an integrated linkage map of common bean. III. Mapping genetic factors controlling host-bacteria interactions. Genetics, v.134, p.341-350, 1993.

ORF, J.H.; CHASE, K.; ADLER, F.R.; MANSUR, L.M.; LARK, K.G. Genetics of soybean agronomic traits: II. Interactions between yield quantitative trait loci in soybean. Crop Science, v.39, p.16521657, 1999a.

ORF, J.H.; CHASE, K.; JARVIK, T.; MANSUR, L.M.; CREGAN, P.B.; ADLER, F.R.; LARK, K.G. Genetics of soybean agronomic traits: I. Comparison of three related recombinant inbred populations. Crop Science, v.39, p.1642-1651, 1999b.

SAS INSTITUTE (Cary, Estados Unidos). SAS/STAT user's guide: version 6. $4^{\text {th }}$ ed. Cary, NC, 1989. 846p.

SCHUSTER, I.; ABDELNOOR, R.V.; MARIN, S.R.R.; CARVALHO, V.P.; KIIHL, R.A.S.; SILVA, J.F.V.; SEDIYAMA, C.S.; BARROS, E.G.; MOREIRA, M.A. Identification of a new major QTL associated with resistance to soybean cyst nematode (Heterodera glycines). Theoretical and Applied Genetics, v.102, p.91-96, 2001.

SEBOLT, A.M.; SHOEMAKER, R.C.; DIERS, B.W. Analysis of a quantitative trait locus allele from wild soybean that increases seed protein concentration in soybean. Crop Science, v.40, p.1438-1444, 2000.

SONG, Q.J.; MAREK, L.F.; SHOEMAKER, R.C.; LARK, K.G.; CONCIBIDO, V.C.; DELANNAY, X.; SPECHT, J.E.; CREGAN, P.B. A new integrated genetic linkage map of the soybean. Theoretical and Applied Genetics, v.109, p.122-128, 2004.

SOUZA, A.A.; BOSCARIOL, R.L.; MOON, D.H.; CAMARGO, L.E.A.; TSAI, S.M. Effects of Phaseolus vulgaris QTL in controlling host-bacteria interactions under two levels of nitrogen fertilization. Genetics and Molecular Biology, v.23, p.155161, 2000.

STOUGAARD, J. Regulators and regulation of legume root nodule development. Plant Physiology, v.124, p.531-540, 2000.

VEST, G.; CALDWELL, B.E. $R j_{4}$ - a gene conditioning ineffective nodulation in soybeans. Crop Science, v.12, p.692-694, 1972.

VINCENT, J.M. A manual for the practical study of root nodule bacteria. Oxford: Blackwell, 1970. 164p.

WRICKE, G.; WEBER, W.E. Quantitative genetics. In: WRICKE, G.; WEBER, W.E. (Ed.). Quantitative and selection in plant breeding. Berlin: W. de Gruyter, 1986. p.41-46.

YUAN, J.; NJITI, V.N.; MEKSEM, K.; IQBAL, M.J.; TRIWITAYAKORN, K.; KASSEM, MY.A.; DAVIS, G.T.; SCHMIDT, M.E.; LIGHTFOOT, D.A. Quantitative trait loci in two soybean recombinant inbred line populations segregating for yield and disease resistance. Crop Science, v.42, p.271-277, 2002.

Recebido em 30 de janeiro de 2005 e aprovado em 16 de maio de 2005 